This item was submitted to Loughborough's Research Repository by the author.

Items in Figshare are protected by copyright, with all rights reserved, unless otherwise indicated.

\title{
Temperature regulation, heat balance and climatic stress
}

PLEASE CITE THE PUBLISHED VERSION

http://www.springer.com/medicine/book/978-3-540-24417-2

\section{PUBLISHER}

Springer-Verlag ( $)$ World Health Organization

\section{VERSION}

AM (Accepted Manuscript)

\section{LICENCE}

CC BY-NC-ND 4.0

\section{REPOSITORY RECORD}

Havenith, George. 2019. "Temperature Regulation, Heat Balance and Climatic Stress". figshare. https://hdl.handle.net/2134/12491. 
This item was submitted to Loughborough's Institutional Repository (https://dspace.lboro.ac.uk/) by the author and is made available under the following Creative Commons Licence conditions.

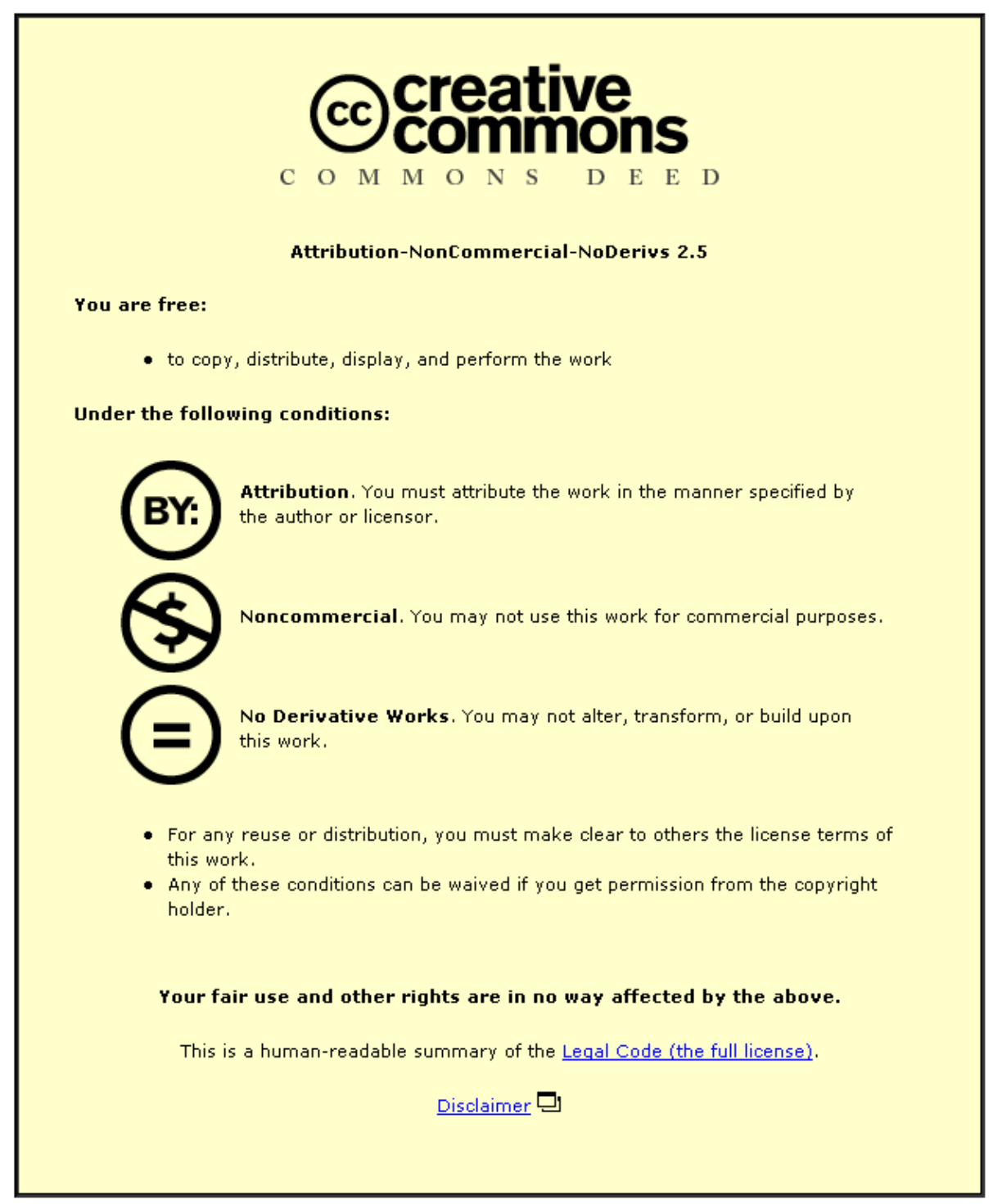

For the full text of this licence, please go to: http://creativecommons.org/licenses/by-nc-nd/2.5/ 
Reference:

Extreme Weather Events and Public Health Responses

2005, Part 2, 69-80, DOI: 10.1007/3-540-28862-7_7

Chapter 7

\title{
Temperature Regulation, Heat Balance and Climatic Stress
}

\author{
GEORGE HAVENITH \\ Human Thermal Environments Laboratory \\ Department of Human Sciences, \\ Loughborough University, LE11 3TU
}

\author{
Version 2004-March \\ For \\ WHO \\ Dr. George Havenith \\ Human Thermal Environments Laboratory \\ Department of Human Sciences, \\ Loughborough University, \\ Ashby Road \\ Loughborough, UK \\ LE11 3TU \\ Telephone: +44 1509223031 \\ Fax: +44 1509223940 \\ E mail: G.Havenith@lboro.ac.uk
}

Keywords: thermoregulation, heat, cold, comfort, vapour, age, stress, strain, mortality, morbidity 


\begin{abstract}
This paper discusses human thermoregulation and how this relates to health problems during exposure to climatic stress. The heat exchange of the body with the environment is described in terms of the heat balance equation which determines whether the body heats up, remains at stable temperature, or cools. Inside the body the thermoregulatory control aims at creating the right conditions of heat loss to keep the body temperature stable. In the heat the main effector mechanism for this is sweating. The heat balance is affected by air temperature, radiant temperature, humidity and wind speed as climatic parameters and by activity rate, clothing insulation and sweat capacity as personal parameters. Heat tolerance is discussed in the light of personal characteristics (age, gender, fitness, acclimatisation, morphology and fat) indicating age and fitness as most important predictors. Heat related mortality and morbidity are strongly linked to age.
\end{abstract}

\title{
1 Introduction
}

Recent extreme weather events have been linked to increased morbidity and mortality. Longer periods of hot weather, especially when little relief is given at night have hit mainly the older population. In order to understand the link between the climate, the stress it poses for the human, and the way the physiological strain experienced by the human is linked to age and other personal characteristics (e.g. a higher mortality was observed in females than in males) this chapter will provide some background knowledge on the parameters relevant to heat stress and strain.

In the evolutionary sense, man is considered a tropical animal. Our anatomy as well as our physiology is geared towards life in moderate and warm environments. There, we can maintain our bodily functions, especially thermoregulation, without artificial means. The goal is to keep the body temperature within acceptable limits and the success of the effector actions will very much depend on the climate conditions and the person's 
clothing and work load. The interaction of the person with the climate is represented by the heat balance equation, which will be discussed in detail. How the person reacts is governed by the human thermoregulatory system. Finally, individual characteristics of the person will affect his or her ability to thermoregulate and affect the risk of heat or cold stress. Problems, in terms of morbidity and mortality, occur when thermoregulation is impaired in conditions of high levels of heat or cold stress.

\section{Temperature Regulation}

In a neutral climate, at rest, the human body regulates its temperature around $37^{\circ} \mathrm{C}$. This is by no means an exactly fixed temperature for all humans. Over a population, when measured in the morning after bed-rest, the mean will be around $36.7^{\circ} \mathrm{C}$, with a standard deviation of $0.35^{\circ} \mathrm{C}$ (calculated from data of Wenzel and Piekarski (1984)). During the day, the temperature will increase (typically by about $0.8^{\circ} \mathrm{C}$ ), peaking in the late evening, and declining again until early morning due to the circadian rhythm. Also, exercise will cause an increase in body temperature; with temperatures around $38^{\circ} \mathrm{C}$ typical for moderate work and values up to $39^{\circ} \mathrm{C}$ and occasionally above $40^{\circ} \mathrm{C}$ for heavy exercise (e.g. marathon). Short term increases up to $39^{\circ} \mathrm{C}$ are seldom a problem to the body and should be considered a normal phenomenon in thermoregulation of a healthy person. In fever, an increase in body temperature is observed as well. This increase differs from that in exercise in that the increase in temperature due to fever is defended by the body, whereas the increase in temperature induced by exercise is not. Thus, when a fever of $38.5^{\circ} \mathrm{C}$ is present, cooling the body will lead to activation of heat conservation mechanisms by the body (shivering, vasoconstriction) to keep the temperature at that level. In exercise, the body would continue sweating until the body temperature is back to neutral levels.

\section{Figure 1}

An example of how the body's temperature regulation could be represented is given in Figure 1. Here we have a body, which is represented by a body core temperature and by a skin temperature. Afferent signals representing these body temperatures are relayed to the control centres in the brain. There they are compared to a reference signal, which could be seen as a single thermostat 
setpoint, or as a number of thresholds for initiating effector responses. Based on the difference between actual temperature and the reference value (the error signal), various effector responses can be initiated. The main ones are sweating and vasodilation of skin vessels (if body temperatures are higher than the reference, i.e. a positive error) and shivering and vasoconstriction (negative error). Sweat evaporation will cool the skin, shivering will increase heat production and heat the core, and vasodilation and constriction will regulate the heat transport between core and skin.

Of course this is a simplified model, as many different thermosensitive regions of the body have been identified, and many different and more complex models are possible.

When we think of clothing we can think of it as an additional, behavioural effector response. If we can freely choose our clothing, which often is not the case due to cultural or work restraints, we adjust our clothing levels to provide the right amount of insulation to allow the other effector responses to stay within their utility range. The main effect of clothing will be its influence on the heat exchange between the skin and the environment. To understand these effects we will need to analyse the heat flows that exist between the body and its environment, in other words we have to look at the body's heat balance.

\section{Heat Balance}

Normally the body temperature is quite stable. This is achieved by balancing the amounts of heat produced in the body with the amounts lost.

\section{Stability: Heat Production $=$ Heat Loss}

In Figure 2, a graphical representation of all the heat inputs to and outputs from the body is presented (Havenith, 1999):

Heat production is determined by metabolic activity. When at rest, this is the amount needed for the body's basic functions, e.g. respiration and heart function to provide body cells with oxygen and nutrients. When working however, the need of the active muscles for oxygen and nutrients increases as does the metabolic activity. When the muscles burn these nutrients for mechanical activity, part of the energy they contain may be liberated 
outside the body as external work, but most of it is released in the muscle as heat. The ratio between this external work and the energy consumed is called the efficiency with which the body performs the work. This process is similar to what happens in a car engine. The minor part of the fuel's energy is actually effective in the car's propulsion, and the major part is liberated as waste heat. The body, as the car engine, needs to get rid of this heat; otherwise it will warm up to lethal levels. As an example: if no cooling would be present, a person working at moderate levels (metabolic rate $450 \mathrm{Watt}$ ) would show an increase in body temperature around $1^{\circ} \mathrm{C}$ every 10 minutes.

\section{Figure 2}

For most tasks, as e.g. walking on a level, the value for the external work (energy released outside the body) is close to zero. Only the heat released by friction of shoes etc. is released outside the body, whereas all other energy used by the muscles ends up as heat within the body. In the cold, additional heat is produced by shivering: muscle activity with zero efficiency. The basal metabolic rate and heat production can be increased up to fourfold in this way.

For heat loss from the body, between skin and environment, several pathways are available. For each pathway the amount of transferred heat is dependent on the driving force (e.g. temperature or vapour pressure gradient), the body surface area involved and the resistance to that heat flow (e.g. clothing insulation).

$$
\text { Heat } \text { Loss }=\frac{\text { gradient } \cdot \text { surface area }}{\text { resistance }}
$$

A minor role is taken by conduction. Only for people working in water, in special gas mixtures (prolonged deep-sea dives), handling cold products or in supine positions, does conductivity becomes a relevant factor.

More important for heat loss is convection. When air flows along the skin, it is usually cooler than the skin. Heat will therefore be transferred from the skin to the air around it. 
Heat transfer through electro-magnetic (mainly infra-red) radiation can be substantial. When there is a difference between the body's surface temperature and the temperature of the surfaces in the environment, heat will be exchanged by radiation. Finally, the body possesses another avenue for heat loss, which is heat loss by evaporation. Any moisture present on the skin (usually sweat) can evaporate, with which large amounts of heat can be dissipated from the body. Apart from convective and evaporative heat loss from the skin, these types of heat loss also take place from the lungs by respiration, as inspired air is usually cooler and dryer than the lung's internal surface. By warming and moisturising the inspired air, the body loses an amount of heat with the expired air, which can be up to $10 \%$ of the total heat production.

For body temperature to be stable, heat losses need to balance heat production. If they do not, the body heat content will change, causing body temperature to rise or fall. This balance can be written as:

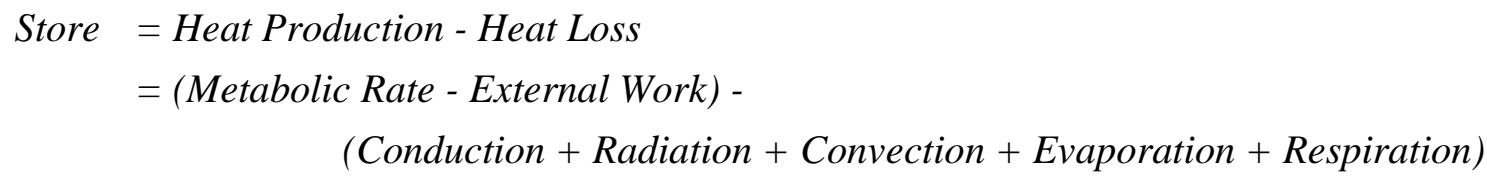

Thus if heat production by metabolic rate is higher than the sum of all heat losses, Store will be positive, which means body heat content increases and body temperature rises. If store is negative, more heat is lost than produced. The body cools.

It should be noted that several of the "heat loss" components might in special circumstances (e.g. ambient temperature higher than skin temperature) actually cause a heat gain, as discussed earlier.

\section{$4 \quad$ Relevant parameters in heat exchange}

The capacity of the body to retain heat or to lose heat to the environment is strongly dependent on a number of external parameters (Havenith, 2004): 


\subsection{Temperature}

The higher the air temperature, the less heat the body can lose by convection, conduction and radiation (assuming all objects surrounding the person are at air temperature). If the temperature of the environment increases above skin temperature, the body will actually gain heat from the environment instead of losing heat to it. There are three relevant temperatures:

Air temperature. This determines the extent of convective heat loss (heating of environmental air flowing along the skin or entering the lungs) from the skin to the environment, or vice versa if the air temperature exceeds skin temperature.

Radiant temperature. This value, which one may interpret as the mean temperature of all walls and objects in the space where one resides, determines the extent to which radiant heat is exchanged between skin and environment. In areas with hot objects, as in steel mills, or in work in the sun, the radiant temperature can easily exceed skin temperature and results in radiant heat transfer from the environment to the skin.

Surface temperature. Apart from risks for skin burns or pain (surface temperature above $45^{\circ} \mathrm{C}$ ), or in the cold of frostbite and pain, the temperature of objects in contact with the body determines conductive heat exchange. Aside from its temperature, the object's properties, as e.g. conductivity, specific heat and heat capacity, are also relevant for conductive heat exchange.

\subsection{Air humidity}

The amount of moisture present in the environment's air (the moisture concentration) determines whether moisture (sweat) in vapour form flows from the skin to the environment or vice versa. In general the moisture concentration at the skin will be higher than in the environment, making evaporative heat loss from the skin possible. As mentioned earlier, in the heat, evaporation of sweat is the most important avenue for the body to dissipate its surplus heat. Therefore situations where the gradient is reversed (higher moisture concentration in environment than on skin) are extremely stressful (condensation on skin) and allow only for short exposures. It should be noted that the 
moisture concentration, not the relative humidity, is the determining factor. The definition of relative humidity is the ratio between the actual amount of moisture in the air and the maximal amount of moisture air can contain at that temperature (i.e. before condensation will occur). Air that has a relative humidity of $100 \%$ can thus contain different amounts of moisture, depending on its temperature. The higher the temperature, the higher the moisture content at equal relative humidities. Also: at the same relative humidity, warm air will contain more moisture (and allow less sweat evaporation) than cool air. The fact that relative humidity is not the determining factor in sweat loss can be illustrated with two examples:

- In a 100\% humid environment the body can still evaporate sweat, as long as the vapour pressure is lower than that at the skin. So, at any temperature below skin temperature the body can evaporate sweat, even if the environment is 100\% humid.

- Sweat evaporation (at equal production) will be higher at $21^{\circ} \mathrm{C}, 100 \%$ relative humidity (vapour pressure is $2.5 \mathrm{kPa}$ ) than at $30{ }^{\circ} \mathrm{C}$, with $70 \%$ relative humidity (vapour pressure $=$ $3 \mathrm{kPa}$ ) as the vapour pressure gradient between wet skin (vapour pressure $5.6 \mathrm{kPa}$ ) and environment at $21^{\circ} \mathrm{C}$ is $5.6-2.5=3.1 \mathrm{kPa}$, whereas at $30{ }^{\circ} \mathrm{C}$ and, $70 \%$ relative humidity it is only $5.6-3=2.6 \mathrm{kPa}$.

\subsection{Wind speed}

The magnitude of air movement effects both convective and evaporative heat losses. For both avenues, heat exchange increases with increasing wind speed. Thus in a cool environment the body cools faster in the presence of wind, in an extremely hot and humid environment, it will heat up faster. In very hot, but dry environments the effects on dry and evaporative heat loss may balance each other out.

\subsection{Clothing insulation}

Clothing functions as a resistance to heat and moisture transfer between skin and environment. In this way it can protect against extreme heat and cold, but at the same time it hampers the loss of superfluous heat during physical effort. For example, if one 
has to perform hard physical work in cold weather clothing, heat will accumulate quickly in the body due to the high resistance of the clothing for both heat and vapour transport. In cases where no freedom of choice of clothing is present, clothing may increase the risk of cold or heat stress. Examples are cultural restrictions (long, thick black clothes for older females in southern European countries) or work requirements (protective clothing; dress codes).

The environmental range for comfort, assuming no clothing or activity changes are allowed, is quite narrow. For light clothing with low activity levels it is around $3.5^{\circ} \mathrm{C}$ wide (ISO7730, 1984). In order to widen this range, one has to allow for behavioural adjustments in clothing and activity. An increase in activity level will move the comfort range to lower temperatures, as will an increase in clothing insulation. E.g. an increase in metabolic rate of 20 Watts (resting levels are 100-160 Watts) pushes the comfort range down by approximately $1^{\circ} \mathrm{C}$, as does an increase in clothing insulation of 0.2 clo (clo is a unit for clothing insulation. For reference, a three-piece business suit is 1 clo; long trousers and short sleeved shirt around 0.6 clo). An increase in air speed will push the comfort range up $\left(1^{\circ} \mathrm{C}\right.$ for $\left.0.2 \mathrm{~m} . \mathrm{s}^{-1}\right)$, i.e. allow for comfort at higher ambient temperatures.

\section{$5 \quad$ Heat Tolerance and Individual Differences}

When a group of people is exposed to a heat challenge (e.g. heat wave, or working in the heat), their body temperature will increase, but not to the same extent for all. Where some may experience extreme heat strain, others may not show any sign of strain at all. Knowledge of the mechanisms behind these differences is important for risk assessment during climatic extremes, for health screening and for selection of workers for specific stressful tasks. In order to get an insight into the relevant mechanisms, factors which may influence the response of an individual to heat exposure are discussed here and include: aerobic power, acclimation state, morphological differences, gender, use of drugs and age (Havenith, 1985, 2001a,b,c, Havenith et al. 1995b). 


\section{Aerobic power (fitness)}

Body core temperature during work is related to the work load (metabolic rate), relative to the individuals' maximal aerobic power (usually expressed as the $\%$ of the maximal oxygen uptake per minute; $\left.\% \dot{\mathrm{V}}_{2 \max }\right)$. In addition, a high aerobic power is typically associated with improved heat loss mechanisms (higher sweat rate, increased skin blood flow). The $\dot{\mathrm{V}}_{2 \max }$ of a subject is thus inversely related to the heat strain of a subject in the heat, mainly through its beneficial effect on circulatory performance. The higher the aerobic power, the higher the circulatory reserve (the capacity for additional increase in cardiac output) when performing a certain task. Further, aerobic power is often confounded with acclimatisation as training can result in an improvement of the acclimatisation state. This is caused by the regular increase in body temperature, which normally occurs with exercise. The result is a reduction of heat strain in warm climates. This effect works both through circulation and through improved sweat response. The only condition where a high $\dot{\mathrm{V}}_{2 \max }$ is not beneficial is for conditions where heat loss is strongly limited (Hot, Humid), while work rate is related to the workers work capacity (same percentage of $\dot{\mathrm{V}}_{2_{\max }}$ ). In this case, the fitter person will work harder, thus liberating more heat in his body than his unfit companion will. As he or she cannot get rid of the heat, they thus will heat up faster than the slower working unfit person will.

\section{Acclimatisation state}

A subject's state of acclimatisation appears to be of great influence on his reaction to heat stress. With increasing acclimatisation state, the heat strain of the body will be strongly reduced, resulting in lower core temperature and heart rate during a given exercise in the heat (Havenith, 2001c). This is related to improved sweat characteristics (setpoint lower and gain higher), better distribution of sweating over the body and higher efficiency of sweating (higher evaporated/produced ratio) and improved circulatory stability (better fluid distribution, faster fluid recruitment from extra-cellular space, reduced blood pressure decrease) during exercise in the heat. The individual state of acclimatisation can 
be changed by regular heat exposures, e.g. due to seasonal changes in the natural climate or by heat acclimation due to regular artificial (e.g. climatic chamber) heat exposure. Subjects living in the same climatic conditions can differ in acclimatisation status, however, mainly due to the above-mentioned difference in regular training activity. The combination of heat and exercise induces most optimal acclimatisation. Not all subjects acclimatise equally well: some subjects do not show acclimatisation effects at all when exposed to heat regularly.

\section{Morphology and fat}

Differences in body size and body composition between subjects affect thermoregulation through their effect on the physical process of heat exchange (insulation, surface/mass ratio) and through differences in the body weight subjects have to carry (Havenith, 1985, 2001). Body surface area determines the heat exchange area for both dry (convective and radiative) and evaporative heat and thereby affects reactions to heat stress. A high surface area is therefore usually beneficial. Body mass determines metabolic load when a subject is involved in a weight-bearing task like walking. This implies that mass correlates positively with heat production. Body mass also determines body heat storage capacity. This is relevant with passive heat exposures, or when heat loss is limited and body temperature increase is determined by storage capacity.

The effect of body fat content is somewhat confounded with that of body mass: Body fat presents a passive body mass, which affects metabolic load during weight-bearing tasks. I.e. a high fat content increases the metabolic load during activity.

In the cold, subcutaneous fat determines the physical insulation of the body (conductivity of muscle $=0.39$, fat $=0.20 \mathrm{Wm}^{-10} \mathrm{C}^{-1}$ ). However, as the fat layer is well perfused by blood flowing to the skin in warm conditions, it is not expected to hamper heat loss during heat exposure. Further, as the specific heat of body fat is about half that of fat free body tissue, people with equal mass but higher fat content will heat up faster at a certain storage rate. With extreme obesity, cardiac function is reduced, which also leads to reduced heat tolerance. 


\section{Gender}

When investigating the effects of subject's gender on heat stress response, investigators found that females had higher core temperatures, skin temperature, heart rates, blood pressure, and setpoints for sweating, in comparison to males. Thus on a population level, women appear to be less tolerant to heat than men, which seems to be reflected in mortality numbers during heat waves. However, on a population level females differ also in many physical characteristics from men, which may confound the gender issue in thermoregulation research. A more precise evaluation of the gender effect was described by authors, who compared gender groups which were matched in many other characteristics ( $\dot{\mathrm{V}}_{2 \max }, \%$ fat, size; Havenith, 1985, Havenith et al. 1995b). They observed in these matched groups that gender differences in thermoregulation are minimal, and that some of these differences are climate specific (females perform better in warm, humid; worse in hot dry climates). On a population basis however, females clearly perform worse than men and, if exercising at the same level as men run a higher risk for heat illness.

Two specific female processes do effect thermoregulation: the menstrual cycle and menopause. The effect of the menstrual cycle at rest (a higher core temperature in the postovulatory phase) is almost absent during exercise and or heat exposure, however. Others found that existing male-female differences during exercise heat stress disappeared with acclimation, or that they were completely absent from the beginning. In addition, the effect of menopause on thermoregulation during heat exposure has been studied. Postmenopausal hot flashes and night sweating provide anecdotal evidence that thermoregulation is affected by oestrogen withdrawal. At equal stress levels higher core temperatures were observed in postmenopausal women compared to young females with equal aerobic power levels. Acute oestrogen replacement therapy reduces cardiovascular and thermoregulatory strain in postmenopausal women. 


\section{Hypertension}

Studies of the role of hypertension in heat tolerance showed reduced circulatory performance in hypertensives compared to normotensives. Though no differences between groups were present in heart rate and core temperature response, reduced forearm blood flows were observed in hypertensives as well as reduced stroke volumes and cardiac output. This indicates a reduced heat transport capacity from body core to the skin and thus an increased risk of overheating. Sweat rate was higher in the hypertensives, however, which apparently compensated for the circulatory differences. It is difficult to estimate whether this compensation will also be effective in other climatic or work conditions. A certain increased risk seems present.

\section{Drugs}

Use of drugs such as alcohol may predispose subjects to heat illness by changes in physiological effector mechanisms and by changes in behaviour. Reviews list drugs that are potentially harmful in heat exposure. The relevant drugs have mainly effects on the body fluid balance, vasoconstrictor/dilator activity and on cardiac function. These include: alcohol, diuretics, anti-cholinergic drugs, vasodilators, anti-histamines, muscle relaxants, atropine, tranquillisers and sedatives, ß-blockers and amphetamines. Especially anti-hypertensive drugs deserve attention because of their widespread use.

\section{Age}

With advancing age our ability to thermoregulate tends to decrease (Havenith et al, 1995b; Inoue et al, 1999; Kenney and Havenith, 1993). This is a multi-factorial process involving many of our physiological systems with an emphasis on the cardiovascular system. The most important factor is that physical fitness tends to decrease with age (Åstrand and Rodahl, 1970; Havenith et al, 1995b) mostly due to a reduced physical activity level in the elderly (DTI, 1999). This implies that any activity performed becomes relatively more stressful with advancing age. It will put more strain on the 
cardiovascular system, and leave less cardiovascular reserve. The cardiovascular reserve is especially relevant to the capacity for thermoregulation as it determines the capacity to move heat for dissipation from the body core to the skin by the skin blood flow. The fitness reduction with age can work like a vicious circle as the increased strain experienced with activity may in itself promote even further activity reduction. Due to a reduced activity level, people also tend to expose themselves less to physical strain in the form of heat or cold exposure. This leads to a loss of heat and cold acclimatisation (Havenith, 1985), which will result in higher strain when the elderly are on occasion exposed to extreme climates. Typically, on a population level these and other changes lead to reduced muscle strength, reduced work capacity, a reduced sweating capacity, a reduced ability to transport heat from the body core to the skin, and a lower cardiovascular stability (blood pressure) in the elderly. These effects will put elderly people at a higher risk in extreme conditions, leading to an increase in morbidity and mortality.

Apart from the physiological changes mentioned above, the percentage of people with illnesses and disabilities increases with age as well. In the UK 41\% of people aged 65-74 and 52\% over 75 reported that their lifestyle was limited by an illness or disability, compared to $22 \%$ of all age groups (DTI, 1998). This also has consequences for well being in various thermal environments.

\section{$6 \quad$ Mortality and morbidity with age}

Of the individual characteristics age seems to be the best predictor of mortality increases at high temperatures. As discussed above, this ageing effect is likely to be a combined effect of changes in all physiological systems with age, many of which can be avoided by staying fit. The main underlying factors with age are reducing fitness levels, which reduce the spare capacity of the physiological systems to deal with the heat, the increasing health problems in other areas (e.g. hypertension) and the concomitant increase in use of drugs.

In order to provide an overview of the problems related to ageing and temperature regulation, we will now discuss those aspects of mortality and morbidity that in the past 
have been associated with high or low temperatures. The main ones are heat stroke, hypothermia, cardiovascular and cerebral stroke, and in-home accidents as falls. Statistical evidence from heat waves in American and Japanese cities shows that mortality increases dramatically with age when temperature increases. Figure 3 shows data on the number of deaths due to heat stroke by age group for the period of 1968 through 1994 in Japan (Nakai et al., 1999). It is evident that there is a sharp increase in deaths due to heat above the 6th decade. The peak daily temperatures when these heat strokes occurred were typically above $38{ }^{\circ} \mathrm{C}$, although a relatively increased heat related mortality in the elderly compared to younger groups has also been observed at lower temperatures. Data from the United States provide a similar picture, with typically above $60 \%$ of heat related deaths during heat waves above the 6th decade of age. While heat stroke deaths among those aged below 64 years were typically exertion induced heat strokes (outdoor sports or occupational hazards), this was not the case in the elderly. As mentioned, they have a very limited cardiovascular reserve, have a reduced sweating capacity, both putting them at higher risk to develop hyperthermia. Apart from heat stroke, the high cardiovascular strain may also set them up for cardiovascular or cerebral stroke.

The analysis of mortality and morbidity data for cold exposure is more complex (Jendritzky et al., 2000), as many cold related problems may not be attributed to the cold in statistics. Only extreme hypothermia cases may be registered as such, but mild hypothermia and in general excursions into the cold can have a severe impact on health too. Suggested causes are the raised blood pressure and the induced haemoconcentration (Donaldson, et al., 1997) which could put additional strain on the cardiovascular system and which may set the elderly up once more for cardiovascular or cerebral stroke.

\section{Figure 3 \\ Figure 4}

Another problem in the elderly is the incidence of falls. The number of falls increases dramatically with age as can be seen in figure 4 . At the age of 84 , the number of falls is over 60 percent higher than at the age of 65 . At the same time the size of this age group is much smaller than that of 65 . There is no clear statistical evidence that these falls are 
related to temperature however. This lack of statistical significance is most likely due to the large number of confounding factors involved in these falls. A relation with cold is however likely. Cold reduces muscle force, and increases stiffness of joints and tendons (Havenith et al., 1995a). Hence, in the elderly where fitness and muscle force are already reduced, cold will aggravate these problems. Further, people will wear more clothing in the cold, increasing the clothing stiffness and thus decreasing the freedom of movement (Havenith, 1999).

\section{Conclusions}

In summary the thermal strain of the body will be affected by climatic parameters such as temperature, the air's moisture content, wind speed, and radiation levels. In good health the body can deal well with heat and cold stress, but when thermoregulation becomes impaired, e.g. by inappropriate clothing and activity levels, or by a reduced efficiency of the thermoregulatory system as typically occurs with ageing, the human is at risk, which is reflected in increased mortality and morbidity numbers during extreme weather events. The increased mortality with increasing age reflects a change in a number of physiological systems that are observed with age. These changes lead to a reduced capacity to deal with external stressors. 


\section{REFERENCES}

1. Åstrand PO, Rodahl K (1970) Textbook of work physiology. McGraw-Hill publ New York

2. Donaldson, GC, Robinson D and Allaway SL (1997) An analysis of arterial disease mortality and BUPA health screening in men, in relation to outdoor temperature. Clin. Sci. 92, pp 261-268.

3. DTI (1998) Avoiding slips, trips and broken hips; older people in the population. Fact sheet Department of Trade and Industry.

4. DTI (1999) Home accidents surveillance system, including leisure activities. HASS 22nd annual report.

5. Havenith G (1985) Individual differences in thermoregulation; a review. Report of TNO-Institute for Perception 1985-C26.

6. Havenith G (1999) Heat Balance When Wearing Protective Clothing, Annals of Occup. Hygiene, 43(5), pp 289-296

7. Havenith G (2001a) Human Surface to Mass Ratio and Body Core Temperature in Exercise Heat Stress - a Concept Revisited. Journal of Thermal Biology,vol 26, no. 4-5 pp 387-393

8. Havenith G (2001b) -Temperature Regulation In The Elderly- Improving Comfort And Reducing Morbidity And Mortality Using Modern Technology. Gerontechnology, 1, sept 2001 pp 41-49

9. Havenith G (2001c) Individualized model of human thermoregulation for the simulation of heat stress response Journal of Applied Physiology, 90: 1943-1954, 2001

10. Havenith G (2004) Thermal Conditions Measurements. In: Handbook of Human Factors and Ergonomics Methods, Neville Stanton, Alan Hedge, Hal W. Hendrick, Eduardo Salas, Karel Brookhuis (Eds), Taylor and Francis

11. Havenith G, Heus R and Daanen HAM (1995a) The hand in the cold, performance and risk. Arctic med. research, 54, suppl.2, pp 1-11

12. Havenith G, Inoue Y, Luttikholt V, Kenney WL (1995b) Age predicts cardiovascular, but not thermoregulatory, responses to humid heat stress. Eur J Appl Physiol 70:88-96

13. Inoue Y, Havenith G, Kenney WL, Loomis JL, and Buskirk ER (1999) Exercise- and methylcholine-induced sweating responses in older and younger men: effect of heat acclimation and aerobic fitness. Int. J.

Biometeor. 42, Iss 4, pp 210-216

14. ISO 7730 (1984) Moderate Thermal Environments -Determination of the PMV and PPD indices and specification of the conditions for thermal comfort. Geneva, International Standardisation Organisation, 1984

15. Jendritzky G, Bucher K, Laschewski G and Walther H (2000) Atmospheric heat exchange of the human being, bioclimate assessments, mortality and thermal stress. Int. J. of Circumpolar Health, 59: 222-227

16. Kenney WL, Havenith G (1993) Heat stress and age: skin blood flow and body temperature. J Therm Biol 18 (5/6):341-344

17. Nakai S, Itoh T and Morimoto T (1999) Deaths from heat stroke in Japan: 1968-1994. Int.J. Biometeorol. 43:124-127

18. Wenzel HG and Piekarski C: Klima und Arbeit, Bayrisches Staatsministerium für Arbeit und Sozialordnung, 1984. 
Figure 1, Schematic representation of the thermoregulatory control system. $T_{\text {core }}=$ body core temperature; $\mathrm{T}_{\text {skin }}=$ mean skin temperature; brain controller graphs show reaction of effector ( $\mathrm{Y}$-axes) to error signal ( $\mathrm{x}$ axes) (copyright G.Havenith, 2002).

Figure 2, Schematic representation of the pathways for heat loss from the body. M=metabolic heat production (reproduced with permission, Havenith, 1999).

Figure 3, Deaths due to heat stroke by age group from 1968 to 1994 in Japan. Data from Nakai et al, 1999.

Figure 4, number of falls in selected UK area; $1=$ slip/trip/tumble; 2=stairs/steps; 3=level; 4=unspecified (Data from DTI, 1999). 
Brain Controllers

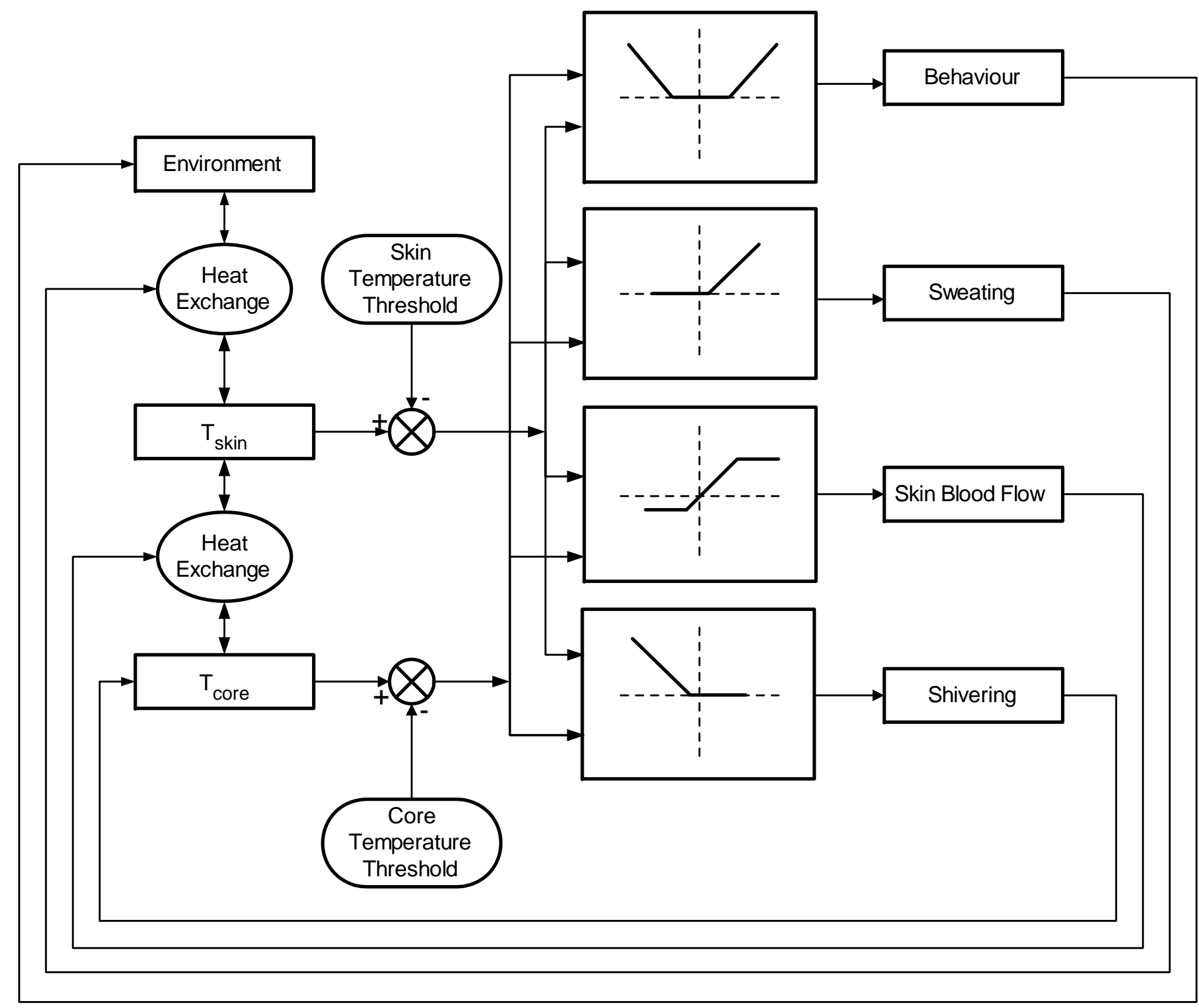

WHO, page 19 


$$
\text { है }
$$




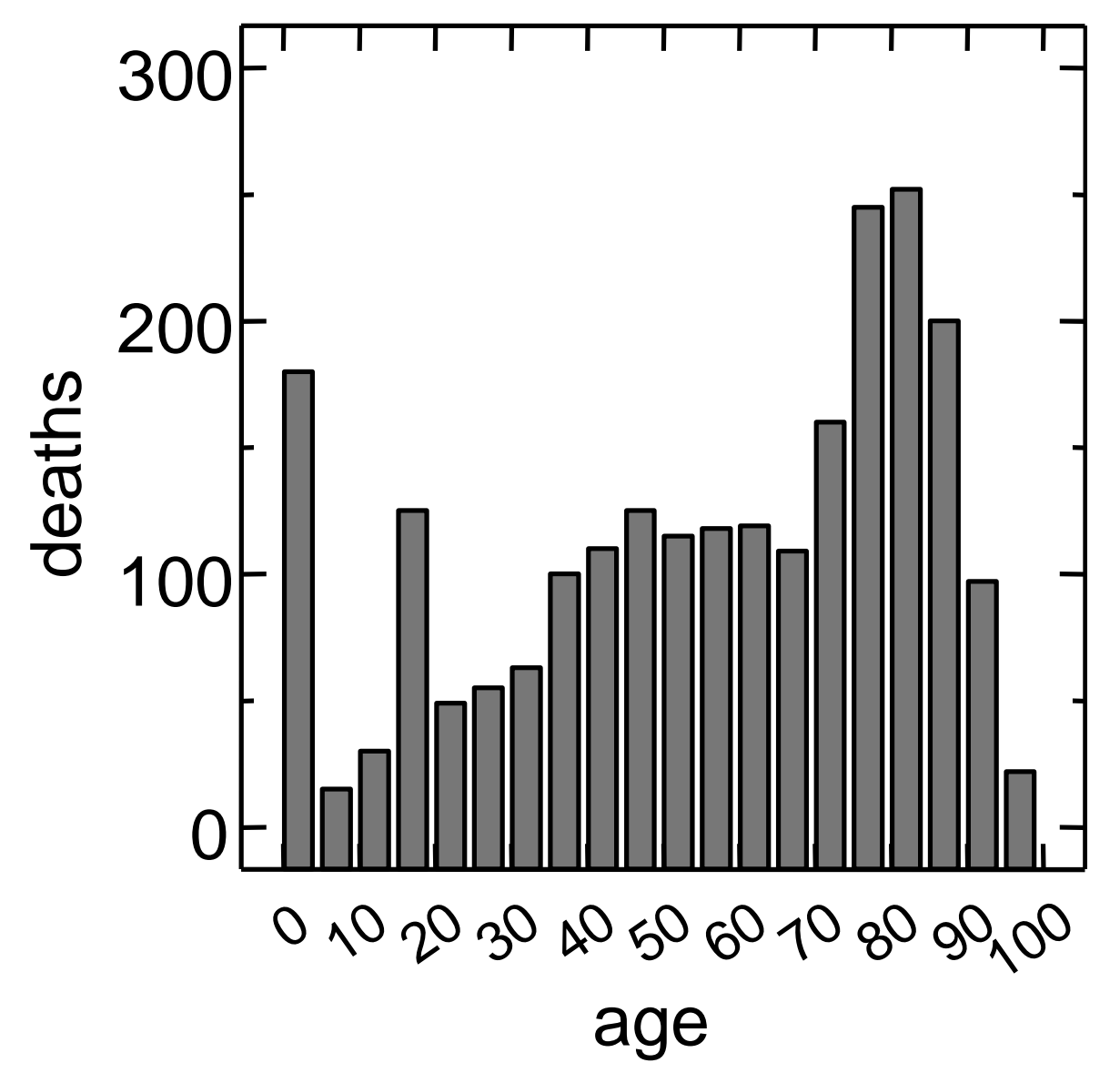

WHO, page 21 


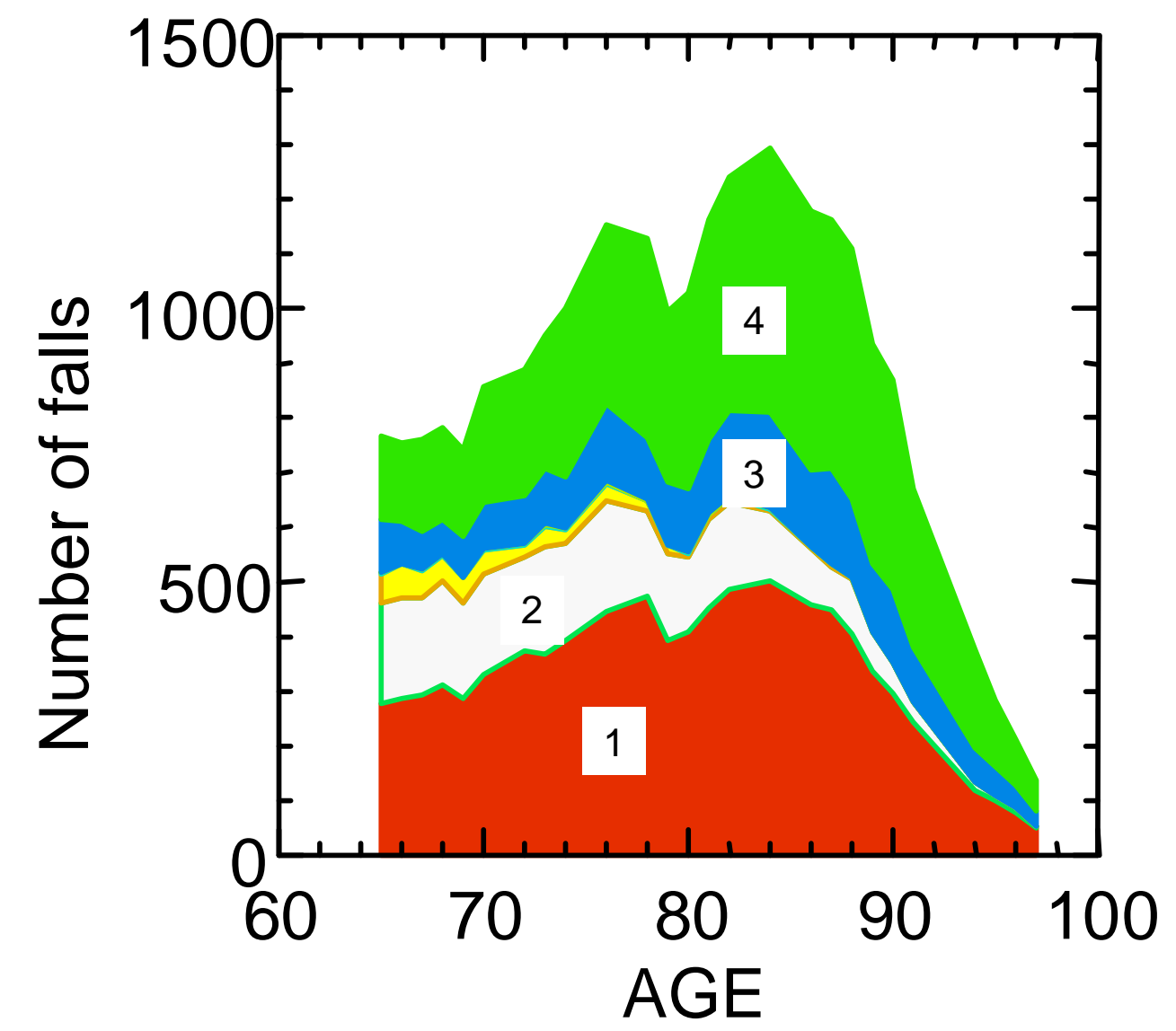

WHO, page 22 